\begin{tabular}{|c|c|c|c|c|c|c|c|}
\hline \multirow{2}{*}{$\begin{array}{l}\text { Type of SPC } \\
\text { Fishmeal replacement } \\
\text { level (\%) }\end{array}$} & \multirow[b]{2}{*}{0} & \multicolumn{3}{|c|}{ High iron } & \multicolumn{3}{|c|}{ Low iron } \\
\hline & & 75 & 95 & 100 & 75 & 95 & 100 \\
\hline Triglycerides $(\mathrm{g} / \mathrm{L})$ & $2.60^{b c}$ & $3.65^{\mathrm{a}}$ & $2.82^{\mathrm{b}}$ & $2.96^{\mathrm{b}}$ & $3.88^{\mathrm{a}}$ & $3.26^{\mathrm{a}}$ & $3.73^{\mathrm{a}}$ \\
\hline Cholesterol total (g/L) & $3.82^{\mathrm{a}}$ & $2.83^{b}$ & $2.19^{\mathrm{c}}$ & $1.89^{\mathrm{d}}$ & $2.62^{b}$ & $2.52^{b}$ & $2.48^{b}$ \\
\hline
\end{tabular}

rainbow trout or European seabass, similar to that of terrestrial vertebrates. In mammals, a dietary excess of iron has been shown to increase plasma triglyceride and cholesterol levels. Given the known variability in the iron content of soybean and in the general context of research on the replacement of dietary fishmeal by plant protein sources in fishfeeds, studies were aimed at verifying the possible effects of dietary iron on plasma lipid concentrations in the rainbow trout. Two trials were undertaken with rainbow trout grown in freshwater at $18{ }^{\circ} \mathrm{C}$. In a first study involving the total replacement of fishmeal by soyprotein concentrates (SPC), it was found that the hypocholesterolemic effect of soyprotein was reduced when the iron content of the SPC was high. In the second trial, a definite doseresponse of plasma cholesterol levels to dietary SPC levels was found with the high iron SPC, whereas no such doseresponse was observed with the the low iron SPC. The hypercholesterolemic effect of iron appears to be dose-dependant.

\section{Low density lipoprotein oxidation in} children. L. Iughetti ${ }^{a}$, C. Volta ${ }^{a}$, E. Maggic $^{\mathrm{c}}, \mathrm{G}$. Bellomo ${ }^{\mathrm{c}}$, S. Bernasconi ${ }^{\mathrm{b}}\left({ }^{1} \mathrm{Clin}-\right.$ ica Pediatrica, Università di Parma e bModena, 'Clinica Medica I, Università di Pavia, Italy).
Several studies have shown that LDL oxidation plays an important role in the pathogenesis of atherosclerosis. Oxidized LDL (oxLDL) are more atherogenic than their native forms because oxidative modifications generate molecular epitopes that provide chemotactic stimuli for monocyte recruitment. They are more avidly taken up by macrophages, thus forming foam cells, which are cytotoxic for endothelial cells. Moreover it has been demonstrated that an in vivo modified LDL could induce an auto-antibody response. Both an enhanced LDL oxidation and high autoantibody anti-oxLDL levels have been shown in several patients characterized by accelerated atherosclerosis as subjects affected by diabetes, essential hypertension, severe carotid atherosclerosis and uremia.

As data exist for children, we studied the oxidation susceptibility of LDL in vitro and the existence of anti-oxLDL autoantibodies in vivo in 18 children and adolescents ( 9 males, 9 females; age $11.02 \pm$ 4.6 years) and in 27 normal adult subjects (13 males, 14 females, age $39.0 \pm 11.1$ years). In all subjects we evaluated:

1) LDL oxidation, triggered by the addition of $\mathrm{CuSO} 4$ and continuously monitored spectrophotometrically at $234 \mathrm{~nm}$ to follow the formation of conjugated dienes. The lag-phase (the most important parameter of oxidability) was significantly more accelerated in children than in 
adults $(117.2 \pm 6.12$ versus $144.0 \pm 20$ min, $P<0.01$ ).

2) The levels of anti-oxLDL autoantibodies, detected with an ELISA method. Anti-oxLDL IgG titers were higher in children $(1.67 \pm 0.41$ versus $1.28 \pm 0.41$ ratio, $P<0.01)$.

3) Vitamin E levels after extraction with hexane by HPLC. No significant difference was present between children $(3.70 \pm 0.62)$ and adults $(3.20 \pm 0.9 \mathrm{nmol} / \mathrm{mgLDL})$.

The increased susceptibility to oxidation of LDL in vitro and the high antibodies titers detected demonstrates that LDL oxidation occurs already during childhood. The possible pathophysiological relevance of these findings is, at the present, obscure and additional work is required.

\section{Neonatal pig enterocytes develop the capacity to oxidize long chain fatty acids. M.T. Morel ${ }^{\mathrm{a}}$, P. Guesnet ${ }^{\mathrm{a}}, \mathrm{C}$. Kohl ${ }^{\mathrm{b}}$, C. Prip-Buus ${ }^{b}$, B. Darcy-Vrillon ${ }^{\mathrm{a}}$, J.P. Pégorier ${ }^{b}$, P.H. Duée (LNSA, Inra, 78350 Jouy-en-Josas; ${ }^{2}$ CEREMOD, CNRS, Meudon-Bellevue).}

The post-natal period is critical for intestinal development. At that time, neonates are fed maternal milk, which is a high-fat diet. The aim of the present work was to investigate the metabolic fate of oleate - a monounsaturated long chain fatty acid - in neonatal pig enterocytes.

Experimental: Enterocytes isolated from the jejuno-ileum of newborn $(0 \mathrm{~d})$ or suckling ( 2 and $13 \mathrm{~d}$ ) pigs were incubated with $1-\left[{ }^{14} \mathrm{C}\right]$ oleate $(1 \mathrm{mM})$ and carnitine $(1 \mathrm{mM})$, with or without glucose ( $5 \mathrm{mM})$. The amount of oleate oxidized versus incorporated into triglycerides (TG), phospholipids (PL), and cholesterol esters was measured. The specific activity of the oleate precursor pool was estimated by taking into account the radioactivity present in triglycerides.
Results: Whatever the age, esterification (TG + PL synthesis) was the main metabolic pathway of oleate metabolism, accounting for $89 \pm 1 \%$ at 0 and $2 \mathrm{~d}$, and for $86 \pm 1 \%$ at $13 \mathrm{~d}$. In all cases, the capacity to esterify oleate was stimulated $(P<0.05)$ by adding glucose to the incubation medium. Taking into account isotopic dilution by endogenous fatty acids, the flux of oleate oxidized was found to increase dramatically after $2 \mathrm{~d}$ of suckling $(6.6 \pm 2.0$ versus $1.3 \pm 0.2 \mathrm{nmol} / 30$ $\mathrm{min} / 10^{6}$ cells; $P<0.05$ ). This was paralleled by a 2.5 -fold increase in mitochondrial carnitine palmitoyl transferase I (CPT I) activity; at the same time, the sensitivity of the enzyme to inhibition by malonylCoA strongly decreased $\left(\mathrm{IC}_{50}\right.$ : $229 \pm 40 \mathrm{nM}$ at $2 \mathrm{~d}$ versus $8 \pm 4 \mathrm{nM}$ at $0 \mathrm{~d})$. This was also accompanied by a significant increase of the CPT I protein.

Conclusions: Although oxidation represents a minor pathway of oleate metabolism in enterocytes, expression of CPT I is required to allow this oxidative capacity to develop after birth.

\section{Treatment effect of growth hormone} substitution in adults on body composition and on dynamic parameters of carbohydrate and energy metabolism. Y. Khalfallah, C. Louche Pelissier, M. Laville, J.P. Riou, G. Sassolas (Inserm U449, Faculté de Médecine R.T.H. Laënnec, 69572 Lyon cedex 08, France).

Growth hormone (GH) action on carbohydrate, lipid and protide metabolisms and on body composition is well known. However, most of these effects were obtained with pharmacological dose of GH during short term trials.

The aim of our study was to determine the metabolic status of 11 secondary GH deficient adults (GHD) before and 1 year after 'physiological' doses of substituted GH. All these patients had a body composition measured by impedancemetry and a 